\title{
Do ecological flows benefit exotic species?
}

\author{
I. Boavida \& A.N. Pinheiro \\ Instituto Superior Técnico, Technical University of Lisbon, Lisbon, Portugal \\ R. Cortes \\ Departamento Florestal, University of Trás-os-Montes and Alto Douro, Vila Real, Portugal
}

\begin{abstract}
Rivers are among the ecosystems that have been most damaged by human pressure, especially in European countries where most streams are regulated. An important instrument to mitigate such impacts is to provide adequate ecological flows, which allows for the preservation of fish populations. Nowadays, many rivers are invaded by exotic species that, being more opportunistic and tolerant, are changing the global biodiversity by competing with native populations. Therefore, while defining ecological flows regimes or during a restoration project design, the existence of exotic species should be taken into account. A project concerning the establishment of an ecological flow regime was undertaken in the Ocreza River, in the eastern center of Portugal. The Instream Flow Incremental Methodology (IFIM) was applied, using the River2D model, to simulate the hydraulic variables and the fish habitat. Close analysis of the results, in terms of WUA values, supported the development of metrics in order to increase the habitat for native species and, at the same time, decrease the habitat for exotic species.
\end{abstract}

\section{INTRODUCTION}

Riverine ecosystems have suffered a long history of degradation, through either direct or indirect human influence. Moreover, freshwater fish are increasingly subject to additional pressures from the introduction of exotic species, here defined as a species that does not occur naturally in that geographical area, i.e. that did not previously occur there or whose dispersal into the area was mediated or facilitated, either directly or indirectly, by humans, whether deliberately or unintentionally (Manchester and Bullock, 2000). These exotic species are increasingly recognized as one of the main threats to biodiversity.

Iberian streams are characterized by peculiar hydrological conditions low flow in the hotsummer drought and flash floods during autumn and spring storms (Gasith and Resh, 1999). Interannual variability in precipitation is high while lengthy periods of drought are common. As a consequence, the native fish fauna is depauperate and highly endemic. In the Iberian Peninsula the native freshwater fish fauna is characterized by a low number of families, a high degree of diversification at the species level and the greatest European percentage of endemism (Doadrio, 2001). The natural variability in environmental conditions of many Iberian streams has been greatly reduced by water regulation. In addition, industrial waste and sewage cause water quality to deteriorate. These profound modifications to the fluvial systems of this region directly threaten the native fish fauna and favor the invasion of non-native species (Copp et al., 2005; Vila-Gispert et al., 2005; Clavero et al., 2004). Introduced species have been successful in the Mediterranean-type climate of California, like Iberian Peninsula, in good part because the natural environment has been so altered. Free-flowing streams have increasingly been turned into reservoirs, regulated streams, and ditches since the early 50s. These artificial systems are occupied almost exclusively by exotic species.

Furthermore, there is an increasing concern over the potential impacts (both adverse and beneficial) of introduced species not only on native species but also on ecosystems and on local and national economies and societies, through either direct or indirect effects (Manchester and Bullock, 2000). The European Water Framework Directive (EC 2000) suggests that the presence of exotic species could prevent an aquatic ecosystem from achieving a "very good" ecological quality rating.

The failure of nonnative species to become established can be attributed mainly to the inexistence of habitat for reproduction and lower levels of tolerance to the degradation of water quality, 
whereas predation by these new piscivorous species may be only a secondary effect. In contrast, native species are adapted to flooding regimes through a combination of life-history strategies and physiological tolerances. After introducing exotic species, their dispersal may be increased by mechanisms and circumstances, such as changes in physical habitat, hydrological regime, water quality, ecosystem and connectivity (Copp et al., 1995). Accordingly, the release of ecological flows could enhance the exotic fish habitat and reduce or alter the native fish populations.

River management efforts to control these species are of crucial importance to maintain biodiversity and protect native species. Therefore, while defining the ecological flows regime or during a restoration project design, efforts should be made towards the maintenance and protection of native species over exotic species, even if it is necessary to adopt other measures such as the implementation of habitat structures or the introduction of spawning substrate that enhance the native species habitat.

\section{MATERIAL AND METHODS}

A study concerning the establishment of an ecological flows regime was undertaken for the Pracana Dam in the Ocreza River, in the eastern center of Portugal. The Ocreza River is a medium-sized river, running on schistose rocks with a catchment area of $1335 \mathrm{~km}^{2}$ and a mean annual flow of $16.5 \mathrm{~m}^{3} / \mathrm{s}$. A $100 \mathrm{~m}$ long study reach, which best represented the river segment (i.e. contains the different type of habitats of the river segment), was selected immediately downstream the dam.

The Instream Flow Incremental Methodology (IFIM) (Bovee et al, 1988) was applied, using the River2D model (Steffler, 2000) to simulate the fish habitat. The river bed topography was surveyed by means of a combined association of a total station with a Global Position System, GPS. Overall, 2001 spots were surveyed at the studied reach. Collected information included the $\mathrm{X}$ and $\mathrm{Y}$ coordinates, bed elevation and substrate composition. To calibrate the model and provide the boundary flow conditions, physical characteristics, including water velocity and depth, were also measured along cross-sections. The bed material and bedform size were surveyed and zoned to establish the effective roughnesses heights.

Fish populations were sampled at undisturbed or minimally disturbed sites of the Ocreza basin (Gorman and Karr, 1978) in early summer. The results showed the existence of an exotic species, the gudgeon Common gudgeon, and four endemic species: the European eel Anguilla anguilla, the barbel Barbus bocagei, the nase Pseudochondostroma polylepis, and the loach Cobitis paludica. Habitat suitability curves (HSC) of depth, velocity and substrate were developed for specific fish size-classes based on reported differences in length and age structure (Bovee, 1986). Sampling was performed by electrofishing with D.C. current and the appropriate voltage to take profit of the induced galvanotaxis on fish behaviour.

The amount of Weighted Usable Area (WUA = area suitable for fish habitat), calculated as a product of depth, velocity and substrate suitability indexes, was computed for each species with the River2D model.

\section{RESULTS}

The sampling results show an insufficient number of individuals for the nase and the loach, so the habitat suitability curves were developed only for gudgeon, European eel and barbel. HSC were determined for two size-classes for the European eel (juveniles $\leq 20 \mathrm{~cm}$; adults $>20 \mathrm{~cm}$ ) and for the barbel (juveniles $\leq 10 \mathrm{~cm}$; adults $>10 \mathrm{~cm}$ ). As for the gudgeon, only one size-class was considered, since the results of gudgeon captures were insufficient to establish two size-classes. Their preference curves are shown in Figures 1 to 3.

The three species exhibit the same velocity preference. Above all, they prefer slow running waters. The maximum preference for the European eel and for the gudgeon occurs at $0.05 \mathrm{~m} / \mathrm{s}$ velocity, whereas for the barbel it occurs between 0.1 and $0.2 \mathrm{~m} / \mathrm{s}$ (Figure 1). While considering depth, these species show clear differences among them. The barbel and the gudgeon tend to prefer shallow waters, although the gudgeon also likes depths about $1 \mathrm{~m}$. Both life-stages of the European eel prefer medium depths (i.e. between 0.4 and $0.6 \mathrm{~m}$ ) (Figure 2). The results concerning the 


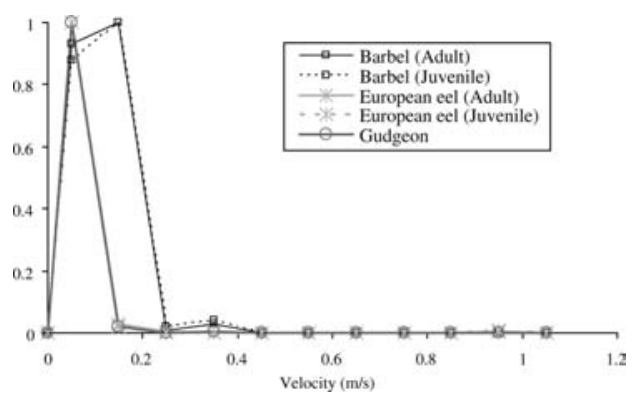

Figure 1. Average water velocity preference curve for the barbel, the European eel and the gudgeon.

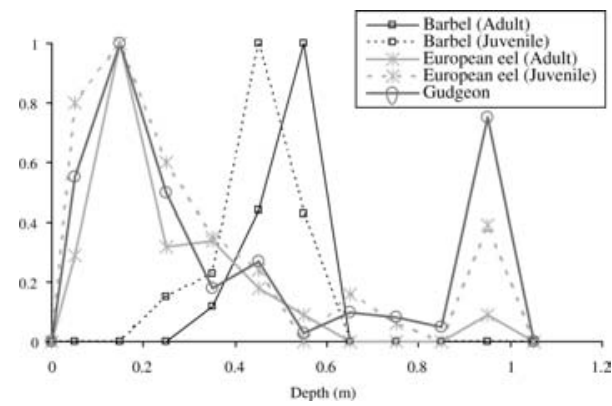

Figure 2. Flow depth preference curve for the barbel, the European eel and the gudgeon.

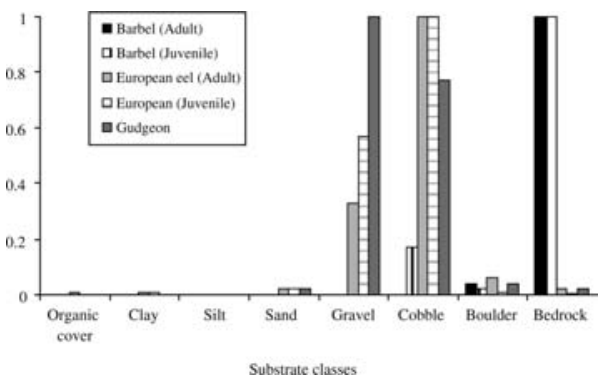

Figure 3. Substrate preference for the barbel, the European eel and the gudgeon.

substrate preference clearly show that the barbel prefers bedrock as substrate, while the European eel and the gudgeon prefer coarse substrate, namely gravel and cobble (Figure 3 ).

The habitat simulation was carried out for a range of flow between 0 and $5 \mathrm{~m}^{3} / \mathrm{s}$. Figure 4 shows the results for the WUA variation with discharge considering the three species. These habitat simulations produced similar results. All species have the same tendency: the WUA increases with the discharge up to a maximum value, which is followed by a decreasing trend.

Overall, the European eel presented the highest WUA values (range: $253-322 \mathrm{~m}^{2}$ ), followed by the gudgeon (maximum: $214 \mathrm{~m}^{2}$ ). The barbel showed the smallest amounts of habitat expressed as WUA, suggesting that this species is less tolerant to this type of habitat. The maximum values of WUA for the European eel and the gudgeon occurred at discharges close to $0.3 \mathrm{~m}^{3} / \mathrm{s}$ and for the barbel between 0.8 and $1 \mathrm{~m}^{3} / \mathrm{s}$.

\section{CONCLUSIONS}

One of the native (eel) and the exotic species (gudgeon) have a maximum habitat for the same discharge. In fact, no significant differences were found between two of the three species. Thus, 


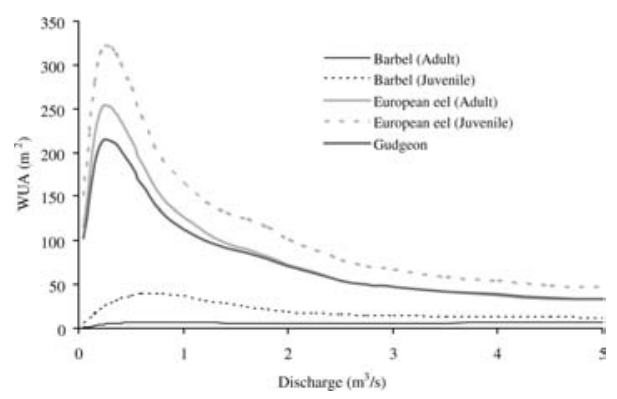

Figure 4. Relationship between WUA and discharge for the barbel, the European eel and the gudgeon.

an ecological flow regime based in the WUA maximum may not be sufficient to differentiate habitat use between the native species and the exotic ones. Other authors documented that the presence of dams is one of the most important factors determining the conservation status of fish communities and it is also positively associated with the number of introduced fishes (Clavero et al., 2004). Moreover, river regulation directly threatens the native fish fauna and favors the invasion of non-native species (Copp et al., 2005).

Despite having the maximum habitat for the same discharge, there are different microhabitat preferences between the native European eel and the exotic gudgeon. In fact, the European eel prefers deeper water, whereas the gudgeon prefers shallow water and coarse substrate. The barbel is different than the other two as it chooses bedrock substrate, higher velocities and its optimum habitat corresponds to higher flows. Therefore, together with the ecological flows regime implementation, it will be necessary to create physical conditions that favour native species. These actions should be towards the enhancement of the spawning habitat (i.e. introduction of spawning substrate) as well as other type of habitat preferred by the native species (i.e. deeper water).

\section{REFERENCES}

Bovee, K. D., Lamb, B. L., Bartholow, J. M., Stalnaker, C. B., Taylor, J., \& Henriksen, J. 1998. Stream Habitat Analysis Using the Instream Flow Incremental Methodology. pp. 130. Fort Collins.

Clavero, M., Blanco-Garrido, F. \& Prenda, J. 2004. Fish fauna in Iberian Mediterranean river basins: biodiversity, introduced species and Hamming impacts. Aquatic Conservation: Marine and Freshwater Ecosystems 14: $575-585$.

Copp, G.H., et al. 2005. To be, or not to be, a non-native freshwater fish? Journal of Appied Ichthyology 21: $242-262$.

Doadrio I (ed.). 2001. Atlas y Libro Rojo de los Peces Continentales de España. Ministerio de Medio Ambiente: Madrid.

EC. 2000. Council Directive for a legislative frame and actions for the water policy, 2000/60/EC, Official Journal of the EC 22/12/2000.

Gasith. A. \& Resh, V.H. 1999. Streams in Mediterranean climate regions - abiotic influences and biotic responses to predictable seasonal events. Annual Review of Ecology and Systematics 30: 51-81.

Gorman, O.T. \& Karr, J.R. 1978. Habitat structure and stream fish communities. Ecology 59: 507-515.

Steffler P. 2000. Software River2D. Two Dimensional Depth Averaged Finite Element Hydrodynamic Model. University of Alberta, Canada.

Manchester, S.J. \& Bullock, J. 2000. The impacts of non-native species on UK biodiversity and the effectiveness of control. Journal of Applied Ecology 37: 845-864.

Vila-Gispert, A., Alcaraz, C. \& Garcia-Berthou, E. 2005. Life-history traits of invasive fish in small Mediterranean streams. Biological Invasions 7: 107-116. 